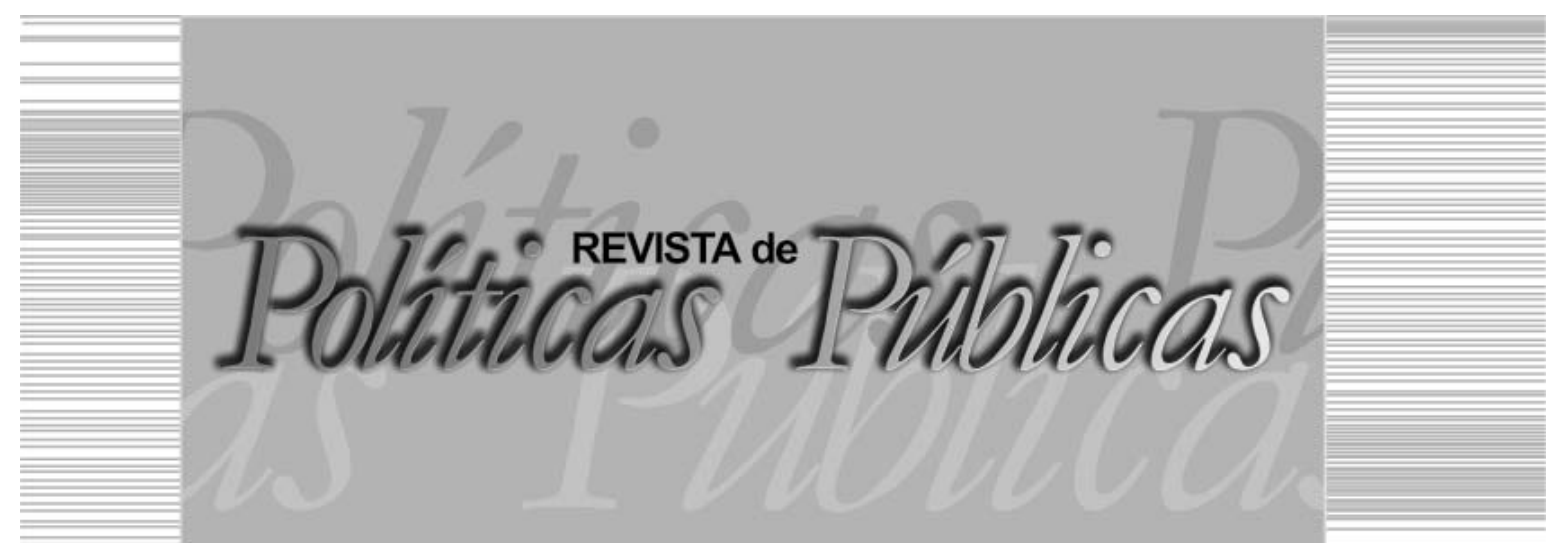

\title{
AS ALTERAÇÕES NA LEGISLAÇÃO DO BENEFICIO DA PENSÃO POR MORTE E SEUS REFLEXOS
}

\author{
Marisangela Caminero Guilhem ${ }^{1}$ \\ Faculdade Meridional do Planalto Médio (IMED) \\ Valkiria Briancini ${ }^{2}$ \\ Faculdade Meridional do Planalto Médio (IMED) \\ Instituto de Desenvolvimento Educacional do Alto Uruguai (IDEAU)
}

\section{Resumo}

Abordagem da Previdência Social como subsistema da Seguridade Social. O objeto do estudo é o benefício previdenciário denominado pensão por morte, concedido aos dependentes do segurado da Previdência Social que vem a falecer, podendo ou não estar aposentado. Esse benefício é uma prestação de caráter contínuo que substitui a remuneração do segurado falecido. $\mathrm{O}$ artigo apresenta as alterações introduzidas pela Lei n. ${ }^{\circ} 13.135 / 2015$ quanto à concessão do benefício em questão e esclarece as razões que ensejaram tais modificações. A pesquisa foi elaborada através do método hipotético-dedutivo por meio de revisão de literatura e análise documental com destaque para a doutrina nacional, súmulas e legislações específicas sobre o tema.

Palavras-chaves: Previdência Social, benefício, pensão por morte, alterações, Lei n. ${ }^{\circ} 13.135 / 2015$.

\footnotetext{
Advogada. Pós-graduada lato sensu em Direito Previdenciário pela Faculdade Meridional do Planalto Médio (IMED) | E-mail: mary.caminero@hotmail.com | Faculdade Meridional do Planalto Médio (IMED) | Rua Senador Pinheiro, n. 304, Passo Fundo - RS | CEP: 99070-220

2 Advogada. Doutoranda em Direito pelo Programa de Pós-Graduação em Direito (Mestrado e Doutorado) da Universidade Estácio de Sá - RJ | Professora do Curso de Direito da Faculdade Meridional (IMED) e do Instituto de Desenvolvimento Educacional do Alto Uruguai (IDEAU) | E-mail: valkiria.briancini@imed.edu.br | Instituto de Desenvolvimento Educacional do Alto Uruguai (IDEAU) | Campus I -Avenida Borges de Medeiros, 2113 , Bairro Champagnet, Getúlio Vargas - RS | CEP: 99.900-000
} 


\title{
CHANGES IN THE LEGISLATION OF THE DEATH BENEFIT PENSION AND ITS CONSEQUENCES
}

\begin{abstract}
Approach to Social Previdence as a social security subsystem. The object of the study is the social security benefit called death pension, granted to dependents of the Social Security insured who is dying, and may or may not be retired. This benefit is a continuous benefit that replaces the deceased insured's remuneration. The article presents the changes introduced by Law 13.135 / 2015 regarding the granting of the benefit in question and clarifies the reasons that led to such modifications. The research was elaborated through the hypothetical-deductive method through literature review and documentary analysis with emphasis on the national doctrine, precedents and specific legislations on the subject.
\end{abstract}

Key words: Social Previdence, benefit, death pension, changes, Law n. ${ }^{\circ}$ $13.135 / 2015$.

\section{INTRODUÇÃO}

A Previdência Social é um dos sistemas de proteção para a população que existe dentro de um todo maior chamado Seguridade Social e busca amparar seus filiados e dependentes que dela necessitam, através de benefícios que são custeados pelo Estado, trabalhadores e empregadores.

Devido ao processo de envelhecimento populacional, decorrente da combinação de queda da fecundidade e aumento da expectativa de vida, haverá um aumento da participação dos idosos na população total e uma piora da relação entre contribuintes e beneficiários, afetando diretamente a pensão por morte. A participação dos idosos na população total deverá crescer de 11,3\% em 2014 para $33,7 \%$ em 2060, conforme dados da projeção demográfica do Instituto Brasileiro de Geografia e Estatística (IBGE). Como resultado, o relatório de avaliação atuarial e financeira do Regime Geral de Previdência Social estima que haverá um crescimento na despesa, do atual patamar de $7 \%$ do Produto Interno Bruto (PIB) para cerca de $13 \%$ PIB em 2050.

O trabalho discorre sobre o benefício da pensão por morte concedido aos dependentes do segurado da Previdência Social que falecer, podendo ou não estar aposentado. Esse benefício é uma prestação de caráter contínuo que vem a substituir a remuneração do 


\section{AS ALTERAÇÕES NA LEGISLAÇÃO DO BENEFÍCIO PENSÃO POR MORTE E SEUS REFLEXOS}

segurado falecido. Em sendo assim, tal prestação, após concedida pelo Órgão Previdenciário, torna-se irrenunciável. Para tanto, será apresentada uma breve evolução histórica do benefício, suas principais características, as alterações normativas realizadas com o passar dos anos, em especial as introduzidas pela Lei n. ${ }^{\circ} 13.135$, de 17 de junho de 2015, procurando esclarecer os motivos que ensejaram tais modificações.

A pesquisa foi elaborada através do método hipotético-dedutivo por meio de revisão de literatura, tendo sido utilizada doutrina nacional, súmulas, legislação e sites de internet.

\section{A EVOLUÇ̃̃O HISTÓRICA DA PENSÃO POR MORTE E AS SUAS PRINCIPAIS ALTERAÇÕES}

O benefício da pensão por morte iniciou, em 1835, com a criação do primeiro Montepio Geral dos Servidores do Estado, no qual seus membros, por meio de cotas, adquiriam o direito de seus beneficiários receberem uma pensão quando os primeiros falecessem. Mais tarde, os funcionários dos Correios e outras pessoas foram aderindo também à ideia dos montepios, garantindo uma parcela ao dependente e não o deixando totalmente desguarnecido no momento de seu óbito. Passava a existir, então, um princípio assistencial, o qual surgiu desde os primórdios da humanidade.

Nesse sentido, o Decreto n. ${ }^{\circ}$ 3.724, de 15 de janeiro de 1919, que tratava da Lei dos Acidentes do Trabalho, responsabilizava objetivamente o empregador por meio de um contrato de seguro regido pelas normas de Direito Civil, com o dever de indenizar os empregados por danos sofridos de acidente de trabalho. Se do acidente resultasse óbito do segurado, era devida uma indenização ao cônjuge e aos herdeiros necessários daquele, a qual corresponderia à soma de três salários do falecido e não poderia superar a dois mil e quatrocentos contos de réis. (SANTOS, 2011).

Posteriormente, em 1923, com a criação da Lei Eloy Chaves $^{1}$, a pensão por morte passou a ser devida no montante de $50 \%$ da aposentadoria para aqueles segurados que contassem com mais de 30 anos de serviço ou, em havendo acidente de trabalho, o benefício seria devido à proporção de $25 \%$ da aposentadoria para os segurados que tivessem entre 10 e 30 anos de serviço. Adiante, mais especificamente no ano de 1936, surgiu o Instituto de Aposentadoria e Pensões dos Industriários (IAPI), que passou a pagar a vantagem 
à razão de 50\% da aposentadoria. Todavia, com o avanço social em 1953, os comerciários se sobressaíram com a criação do Instituto de Aposentadoria e Pensões dos Comerciantes (IAPC), o qual pagava a quantia de $30 \%$ da aposentadoria a que o segurado teria direito, acrescido de $10 \%$ para cada dependente, totalizando o percentual máximo de $100 \%$. (MARTINS, 2014).

A Lei n. ${ }^{\circ} 3.807$, de 26 de agosto de 1960, denominada Lei Orgânica da Previdência Social (LOPS), trouxe algumas alterações importantes, como o prazo de carência do benefício da pensão por morte, o qual passou a ser de 12 contribuições mensais e garantiu, assim, a pensão aos dependentes dos segurados aposentados ou não que viessem a óbito. $\mathrm{O}$ art. $37^{\circ}$ da citada lei determinou que a pensão não fosse inferior ao montante de $50 \%$ do valor da aposentadoria que era recebida ou que tivesse o direito de receber, sendo rateada em partes iguais aos dependentes do de cujus. No entanto, este artigo foi revogado pela Lei . $^{\circ} 5.890$, de 8 de junho de 1973 e cedeu lugar ao dispositivo que compreendia os $50 \%$ a que teria direito ou que era recebido de aposentadoria e tantas parcelas de $10 \%$ no valor da aposentadoria para quantos fossem os dependentes, até o máximo de 5. (MARTINS, 2014).

Vale, ainda, destacar que aos dependentes dos trabalhadores rurais, a pensão por morte somente passou a ser paga após a publicação da Lei n. ${ }^{\circ}$ 4.214, de 2 de março de 1963, ou seja, depois da criação do Fundo de Assistência ao Trabalhador Rural (FUNRURAL).

A Lei n. ${ }^{0} 5.890 / 1973$, em seu art. $3^{\circ}, \S 5^{\circ}$, inciso III, previu que o valor mensal do benefício da pensão por morte não poderia ser inferior a $60 \%$ do salário de $\mathrm{u} \mathrm{m}$ adulto que estivesse em vigor na localidade do trabalho do segurado. (MARTINS, 2014).

A partir da Constituição Federal (CF) de 1988, a Previdência Social passou a ser organizada sob a forma de regime geral de contribuição e filiação obrigatória, preservando o equilíbrio financeiro relativo à atividade e concedendo a pensão por morte tanto do segurado homem, como do segurado mulher a seus cônjuges ou companheiros e dependentes, a quem quer que fosse devida. Observa, ademais, o texto constitucional, que nenhum benefício que substitua o salário de contribuição ou o rendimento do trabalho do segurado pode ter valor inferior a um salário-mínimo, conforme disposto no art. $201^{\circ}$, inciso V, $\S 2^{\circ}$, da Carta Magna. Essa regra passou a ser re- 


\section{AS ALTERAÇÕES NA LEGISLAÇÃO DO BENEFÍCIO PENSÃO POR MORTE E SEUS REFLEXOS}

gulamentada pela Lei n. ${ }^{\circ} 8.213$, de 24 de julho de 1991, que trata da Lei Orgânica da Previdência Social.

Durante a evolução do benefício da pensão por morte, a alteração mais significativa sofrida ocorreu na renda paga aos dependentes. Porém, outras mudanças importantes serão abordadas a seguir.

$\mathrm{O}$ art. $75^{\circ}$ da Lei n. ${ }^{\circ} 8.213 / 1991$, em seu texto original, determinava que o valor da pensão por morte à família seria formado por uma parcela de $80 \%$ do valor da aposentadoria que o segurado recebia ou teria direito a receber na data do óbito acrescido de parcelas de $10 \%$ do valor da aposentadoria, conforme o . $^{\circ}$ de dependentes que tivesse, até o máximo de 2; e, caso o falecimento ocorresse por acidente de trabalho, a cifra relativa à vantagem equivaleria a 100\% do salário de benefício, ou à integralidade do salário de contribuição que estivesse vigente no dia do acidente, se este fosse mais vantajoso. (BRASIL, 1991).

No entanto, este artigo foi alterado pela Lei n. ${ }^{\circ} 9.032$, de 28 de abril de 1995 , e o valor da pensão por morte, incluindo também aquela decorrente de acidente de trabalho, passou a consistir em uma renda mensal correspondente a $100 \%$ do salário de benefício. Ou seja, desapareceram as quotas e a parcela familiar, e a base de cálculo passou a ser o salário benefício, ao invés da aposentadoria do segurado falecido. (SANTOS, 2011).

Novamente, o dispositivo 75 da Lei n. ${ }^{\circ} 8.213 / 1991$ foi modificado, agora pela Lei ${ }^{\circ}{ }^{\circ} 9.528$, de 10 de dezembro de 1997, cujo valor mensal da pensão por morte passou a ser de $100 \%$ do valor da aposentadoria que o segurado recebia ou teria direito a receber, se na data do óbito fosse aposentado por invalidez. Assim, é possível perceber que o percentual permaneceu inalterado, porém mudou a base do cálculo, que passou novamente a ser a aposentadoria do segurado. Também, não se versou mais sobre família e dependentes, mas tão somente sobre a família, sem importar o número de dependentes, a não ser para a divisão do valor. (MARTINS, 2014).

Essas alterações na legislação levaram à propositura de muitas ações que pleiteavam a revisão da Renda Mensal do Benefício (RMI) para aqueles benefícios que haviam sido concedidos antes da vigência da Lei $\mathrm{n}^{\circ}$ 9.032/1995, requerendo fossem os mesmos majorados e calculados com os $100 \%$. Assim, a Turma Nacional de Uniformização dos Juizados Especiais Federais (TNU) editou a Súmula 
n. ${ }^{\circ} 15$, que concedia literalmente aquilo que estavam requerendo, no caso a revisão e o cálculo com os $100 \%$ para as pensões outorgadas antes da vigência Lei . $^{\circ}$ 9.032/1995. No entanto, em 26 de março de 2007, a própria TNU cancelou o enunciado, fazendo com que a discussão fosse levada até o Superior Tribunal Federal (STF). $\mathrm{Na}$ oportunidade, o Ministro Gilmar Mendes adotou o posicionamento majoritário, dizendo que deveria prevalecer a legislação que se encontrava vigente na data do óbito do segurado. Posteriormente, o Superior Tribunal de Justiça (STJ) publicou a Súmula 340, que seguia a decisão do Ministro Gilmar Mendes do STF, dispondo que "[...] a lei aplicável à concessão de pensão previdenciária por morte é aquela vigente na data do óbito do segurado." (SANTOS, 2011, p. 290-291).

Note-se que não havia mais embasamento para que a lei nova retroagisse, deixando a Previdência Social de se importar com a norma mais benéfica aos dependentes do segurado e passando a preservar o equilíbrio financeiro do sistema.

\section{CARACTERISTICAS E ALTERAÇÕES INTRODUZIDAS PELA LEI N. ${ }^{0}$ 13.135/2015}

A pensão por morte, conforme prevê o artigo 74 da Lei ${ }^{\circ}$ 8.213/1991, é um benefício concedido aos dependentes do segurado que falecer, podendo ou não estar aposentado. (BRASIL, 1991). Esse benefício é uma prestação de caráter contínuo que vem a substituir a remuneração do segurado falecido. Em sendo assim, tal prestação, após concedida pelo Órgão Previdenciário, torna-se irrenunciável. (CASTRO; LAZZARI, 2007).

A morte do segurado pode ser real ou presumida. A primeira (real) verifica-se com o efetivo falecimento, sendo a prova feita com a certidão de óbito. A segunda (presumida) divide-se de duas formas. No caso de acidente, desastre ou catástrofe, vale a data do acontecimento. $\mathrm{Ou}$, na ausência (ou desaparecimento) do segurado falecido, deverá a morte ser declarada por decisão judicial. (ROCHA; BALTAZAR JÚNIOR, 2009). Nos dois primeiros casos (morte real), a prestação será paga desde a data do óbito, se requerida até 90 dias, a contar da ocorrência da mesma, ou da data do requerimento, após esse período. E, no último caso (morte presumida), se a morte for declarada por meio de decisão judicial pela autoridade competente depois de 6 meses de ausência, nos termos 


\section{AS ALTERAÇÕES NA LEGISLAÇÃO DO BENEFÍCIO PENSÃO POR MORTE E SEUS REFLEXOS}

do art. $78^{\circ}$ da Lei do Plano de Benefícios será concedida a pensão provisória. Caso, todavia, o segurado reapareça antes desse tempo, o pagamento do benefício será cessado imediatamente, mas os beneficiários não estarão obrigados a devolver os valores recebidos até então, exceto em caso de má-fé.

Destaca-se, conforme o art. $16^{\circ}$ da Lei n. $^{\circ} 8.213 / 1991$, que os beneficiários são divididos em ordem de classes, sendo que a existência de uma exclui as seguintes. Também os integrantes de cada uma concorrem em igualdade de condições e, havendo mais de um beneficiário, o valor é dividido em partes iguais entre eles, bem como o mesmo somente é revertido aos demais quando cessar o direito à pensão de algum deles (BRASIL, 1991, art. $77^{\circ}$, caput e $\S$ $1^{\circ}$ ). A primeira classe é composta pelo cônjuge, companheira e filho menor de 21 anos não emancipado, inválido ou que tenha deficiência intelectual mental ou grave. A segunda é constituída pelos pais; e, a terceira, pelo irmão não emancipado que seja menor de 21 anos inválido ou que tenha deficiência intelectual mental ou grave.

O enteado e o menor tutelado são equiparados ao filho e terão direito à pensão, desde que não possuam bens suficientes para arcarem com seu sustento e educação, devendo comprovar sua dependência econômica.

O ex-cônjuge divorciado ou separado judicialmente, que depende de pensão alimentícia fornecida pelo falecido, tem direito a concorrer como dependente preferencial (IBRAHIM, 2015), assim como aquele que renunciou a tal direito e lhe sobreveio necessidade econômica será considerado dependente para os fins de pensão, conforme Súmula 366 do STJ. (MARTINS, 2014).

Não terão direito à pensão por morte o condenado após o trânsito em julgado da sentença condenatória pela prática de crime que dolosamente cometeu resulte na morte do segurado e o cônjuge ou companheiro que simule ou cometa fraude em casamento ou união estável com o fim exclusivo de receber o benefício previdenciário, o que será apurado em processo judicial, sendo assegurado o direito ao contraditório e à ampla defesa, conforme os $\S \S 1^{\circ}$ e $2^{\circ}$, do art. $74^{\circ}$, da Lei n. ${ }^{\circ} 8.213 / 1991$, acrescidos pela Lei n. ${ }^{\circ}$ 13.135/2015.

Em 2014, a Presidente da República Dilma Rousseff sancionou a Medida Provisória (MP) n. ${ }^{\circ}$ 664, de 30 de dezembro, que trouxe algumas alterações significativas ao benefício em estudo, 
sendo a mais importante delas a carência de 24 contribuições mensais para fazer jus à pensão por morte. Porém, a MP vigorou até o dia 17 de junho de 2015, quando foi modificada e sancionada a Lei n. ${ }^{\circ} 13.135 / 2015^{2}$.

Foram introduzidas mudanças com relação aos valores do benefício. Enquanto esteve em vigor a MP n.$^{\circ}$ 664/2014, os dependentes recebiam o valor de $50 \%$ da aposentadoria que o segurado recebia ou daquela que teria direito, se fosse aposentado por invalidez na data do óbito, o que representaria uma cota fixa familiar, acrescida de $10 \%$ para cada dependente, até o limite de 5, isto é, sem ultrapassar $100 \%$ do valor. (BRASIL, 2014). Tal regra, porém, não foi mantida com a superveniência da Lei n. ${ }^{\circ} 13.135 / 15$, voltando a entrar em vigor o art. $75^{\circ}$ da Lei n. ${ }^{\circ} 9.528 / 1997$, em que o valor do benefício passou a ser de $100 \%$ da aposentadoria que o segurado recebia ou que teria direito a receber, se estivesse aposentado por invalidez na data do falecimento, observando, ainda, que essa renda mensal do benefício não poderia ser inferior ao salário mínimo e nem superior ao limite do salário de contribuição, conforme redação do art. $33^{\circ}$ da Lei n. ${ }^{\circ} 8.213 / 1991$.

A nova lei trouxe consigo outros prazos para a percepção da pensão por morte para os cônjuges ou companheiros, levando em consideração a expectativa de sobrevida da população brasileira, a idade dos beneficiários e o déficit orçamentário da previdência.

Assim, o pagamento da cota individual da pensão, conforme dispõe o art. $77^{\circ}$ da Lei n. ${ }^{\circ} 8.213 / 1991$, somente será cessado para o cônjuge ou companheiro inválido ou com deficiência pelo término da invalidez ou afastamento da deficiência (observa- se que essa regra também inclui o cônjuge ou companheiro do segurado que vier a óbito em decorrência de acidente de qualquer natureza ou por doença profissional ou do trabalho, independente do recolhimento das 18 contribuições ou dos dois anos de casamento ou união estável).

Caso o óbito ocorra sem que o segurado tenha recolhido 18 contribuições mensais ou se o casamento ou união estável tiverem sido iniciados a menos de 2 anos, o cônjuge ou companheiro receberá o benefício somente por 4 meses.

Já quando o óbito ocorrer após as 18 contribuições e pelo menos dois anos após o início da união estável ou do casamento, o benefício cessará da seguinte forma: em 3 anos para os menores 


\section{AS ALTERAÇÕES NA LEGISLAÇÃO DO BENEFÍCIO PENSÃO POR MORTE E SEUS REFLEXOS}

de 21 anos de idade; em 6 anos para aqueles entre 21 e 26 anos de idade; em 10 anos entre os de 27 e 29 anos de idade; em 15 anos para aqueles que têm entre 30 e 40 anos; em 20 anos para faixa etária dos 41 até os 43 anos de idade; será vitalícia para os maiores de 44 anos; e, com a extinção do último beneficiário, extinguir-se-á também a pensão.

Assim, observa-se que foram impostos limites de faixas etárias e, com eles, o tempo de percepção do benefício. Com isso, foi diminuindo, gradativamente, o pagamento dos benefícios e, consequentemente, o gasto que a Previdência Social tinha com os seus segurados, fundamentado pelos mais diversos motivos que, em partes, serão abrangidos adiante.

\section{MOTIVOS QUE LEVARAM Às ALTERAÇÕES INTRODUZIDAS PELA MEDIDA PROVISÓRIA N. 664/2014 NA PENSÃO POR MORTE}

O caput do art. $201^{\circ}$ da CF dispõe que a Seguridade Social deverá observar critérios que preservem o equilíbrio financeiro e atuarial. Para tanto, a base de financiamento da Seguridade Social é diversificada, conforme o art. $195^{\circ}$ da Carta Magna, e prevê que haja um equilíbrio entre todas as despesas, sendo feito de forma direta e indireta, mediante recursos advindos do orçamento da União, dos Estados, do Distrito Federal, dos Municípios e de muitas contribuições sociais, tais como a do empregador, do trabalhador, dos segurados da previdência social, da receita de concursos prognósticos, do importador de bens ou de serviços.

O caput do art. $201^{\circ}$ da CF é um dos princípios mais importantes do sistema previdenciário, pois é evidente que deve existir um controle tanto de entrada, quanto de saída das receitas, tanto para o pagamento dos benefícios atuais, quanto para os futuros. Quando um regime previdenciário inicia, sua renda tende a ser muito mais elevada do que os gastos com pagamentos de benefícios e serviços, sendo que nos primórdios serão devidas somente aquelas prestações que não foram programadas, tornando equilibrada sua receita. Caso essa receita, todavia, não cubra as despesas, haverá um desequilíbrio monetário, o que, por exemplo, ocorre no Regime Geral da Previdência Social (RGPS), quando somados os números urbanos e rurais; no entanto, esse déficit vem sendo reduzido com as corriqueiras mudanças na legislação. (AMADO, 2016). Quando não existem 
boas reservas para garantir um futuro sólido à previdência, sendo observadas tendências que lesem os caixas, como, por exemplo, o aumento da expectativa de vida, o número de acidentes de trabalho, a diminuição da taxa de natalidade, os aposentados constituindo novos casamentos com pessoas mais novas deixando a pensão por morte de ser paga por muito tempo (AMADO, 2016), reformas são necessárias no sistema.

Nessa linha de raciocínio, tem-se um dos principais fundamentos da Previdência Social para alterar a faixa etária do benefício de pensão por morte, que é a readequação do sistema Previdenciário devido ao aumento da expectativa de vida da população brasileira. Conforme dados colhidos pelo IBGE, a expectativa de vida ao nascer aumentou de 74,9 anos em 2013 para 75,2 anos em 2014, segundo a tabela de Mortalidade de 2013. São estimativas consideráveis, uma vez que anualmente a tendência continua sendo a mesma. (EXPECTATIVA..., 2015). Isso ocorre devido "[...] à queda da taxa de fecundidade, entendida como o número de crianças nascidas vivas de mulheres em idade reprodutiva, num determinado período de tempo." (DEPARTAMENTO INTERSINDICAL DE ESTATÍSTICA E ESTUDOS SOCIOECONÔMICOS, 2012, p. 25).

Corroborando esse fato, adveio a proposta da MP $n .^{\circ}$ 664/2014, fundamentada no motivo exposto, qual seja, o processo de envelhecimento da população, que decorre da combinação da queda da fecundidade nas mulheres com o aumento da expectativa de vida. Conforme dados expostos, a população idosa cresceria de 11,3\% em 2014 para 33,7\% em 2060, segundo dados fornecidos pelo IBGE, estimando um aumento de despesas no patamar de $7 \%$ atualmente para 13\% em 2050. (ALVES FILHO; BELCHIOR; MANTEGA, 2014).

Ademais, ressalta-se que a despesa bruta com a pensão por morte aumentou de 39 bilhões em 2006 para 86,5 bilhões em 2013, ultrapassando o dobro da cifra original no período de tempo avaliado. Isto é, houve uma alta de $121,5 \%$ no decorrer de sete anos, o que representa mais ou menos $12 \%$ a cada 12 meses (Gráfico 1). Com relação ao PIB, houve o aumento de pagamento só em pensões de cerca $1,6 \%$ em 2006 para $1,8 \%$ em 2013 somente no RGPS (Gráfico 2). A quantidade de pensões concedidas passou de 5,9 milhões em dezembro de 2005 para 7,4 milhões em outubro de 2014. Ocorreu, praticamente, um acréscimo de 1,5 milhões, sendo 


\section{AS ALTERAÇÕES NA LEGISLAÇÃO DO BENEFÍCIO PENSÃO POR MORTE E SEUS REFLEXOS}

que a média de duração dos benefícios cessados alterou-se de 13 anos em 1999 para 16 anos em 2012. Por ora, é informado que essas pensões tiveram uma duração média de 35 (trinta e cinco) anos ou mais e que "[...] o incremento da despesa por si só não é um problema, quando representa maior nível de proteção, mas certamente não é recomendável quando decorre de regras inadequadas de concessão e também pressiona a carga tributária." (ALVES FILHO; BELCHIOR; MANTEGA, 2014, p. 2).

Gráfico 1 - Despesa da pensão por morte RGPS (em $\mathrm{R} \$$ bilhões nominais de 2006-2013)

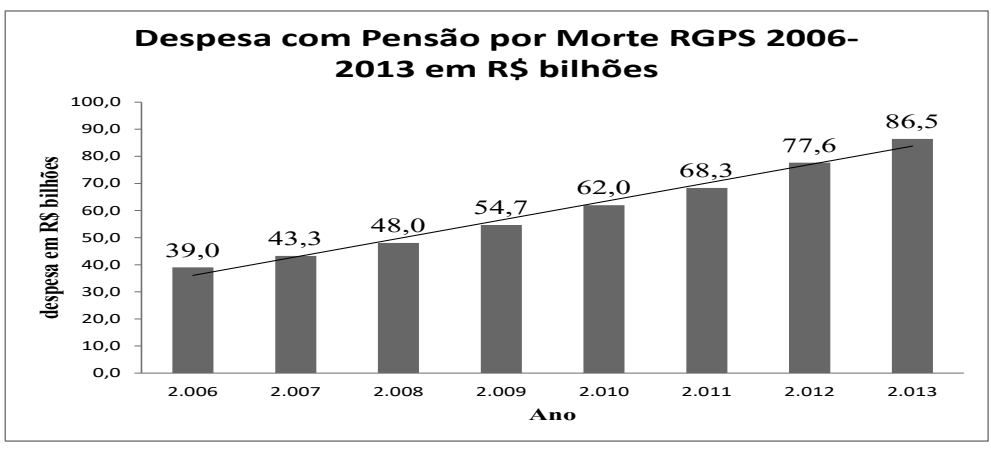

Fonte: ALVES FILHO, Garibaldi; BELCHIOR, Miriam Aparecida; MANTEGA, Guido. EMI n 00023/2014 MPS MF MP. Exposição de Motivos da Medida Provisória no 664 de 30 de dezembro de 2014. In: Diário Oficial da República Federativa do Brasil, Brasília, DF, 02 jan. 2015. p. 2. Disponível em: <http://www.planalto.gov.br/ccivil_03/_Ato2011-2014/2014/Mpv/mpv664.htm>. Acesso em: 2 de mar. 2016.

Gráfico 2 - despesa da pensão por morte RGPS em \% do PIB de 2006-2013

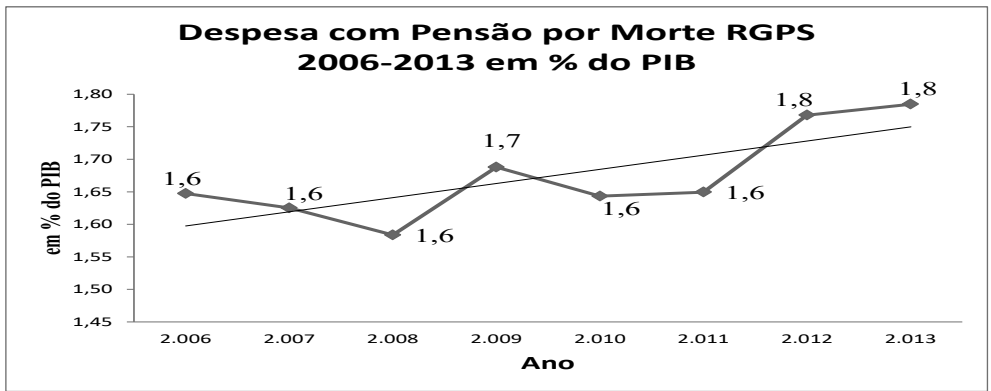

Fonte: (ALVES FILHO; BELCHIOR; MANTEGA, 2014, p. 2). 
No que tange aos cônjuges, companheiros ou companheiras dependentes do segurado gerador do benefício, na exposição de motivos da MP n. ${ }^{\circ}$ 664/2014, foram apresentados a ausência de um tempo mínimo de casamento ou união estável, bem como que o benefício é vitalício para cônjuges, companheiros ou companheiras, independentemente da idade. A maioria dos países exige carência, tempo mínimo de casamento e tem tratamento diferenciado, dependendo da idade do cônjuge. (ALVES FILHO; BELCHIOR; MANTEGA, 2014).

Vale destacar que a reestruturação do benefício da pensão por morte fazia parte de uma das medidas a serem tomadas no Programa de Reequilíbrio Macroeconômico como base para a retomada do crescimento pelo Governo, consoante dado retirado do site do Senado Federal do Resumo da Política Econômica do Governo. (FAGNANI, 2016).

Além dessas alterações, seria necessária a ocorrência de um avanço no ritmo da remuneração percebida pelos trabalhadores com relação ao crescimento dos benefícios. Porém, a situação atual vai justamente para o lado oposto, uma vez que os desempregados provavelmente não irão gerar contribuição para aumentar a receita previdenciária, sem contar que a taxa de desemprego para os cargos com alta renda, ao que se apura, também prosperam, uma vez que essas pessoas estão sendo contratadas, por seus antigos empregadores (que antes recolhiam 20\% incidentes sobre a folha de salário deles), na forma de pessoas jurídicas e estão contribuindo como autônomos hoje. Deveriam, ainda, fiscalizar mais as relações de trabalho, taxar o produtor rural pessoa jurídica que exporta seu produto, levar mais em consideração a sobrecarga feminina trazida pela história, pois essa pode ser uma das causas da diminuição nas taxas de fecundidade, visto que necessitam trabalhar mais do que os homens. (MELO, 2016).

Por outro lado, há economistas que entendem não haver prejuízos para a Seguridade Social, e a população, frente a esses fatores expostos e a concessão de muitos outros benefícios, acreditam existir apenas maquiagens econômicas para alardear tais fatos.

Nesse sentido, segundo Eduardo Fagnani, um estudo efetuado pelo Instituto de Pesquisa Econômica Aplicada (IPEA), publicado no ano de 2006, demonstra que, na maioria dos países da Organização para a Cooperação e Desenvolvimento Econômico (OCDE), 


\section{AS ALTERAÇÕES NA LEGISLAÇÃO DO BENEFÍCIO PENSÃO POR MORTE E SEUS REFLEXOS}

são gastos em torno de $27,3 \%$ do PIB com seguridade social, em que os empregadores financiam $38 \%$, os empregados $22 \%$ e o governo contribui com $36 \%$. Já em 2012, no Brasil, foram utilizados R \$ 317 bilhões para pagar benefícios previdenciários. Contudo, somente as contribuições dos empregados e empregadores somaram o montante de $\mathrm{R} \$ 279$ bilhões (88\%), participando, assim, o governo com a parcela de apenas $12 \%$, um montante inferior à terça parte do custeio tripartite, o que "[...] serve, unicamente, para criar, alardear um falso déficit e justificar mais reformas, com o corte de direitos. São invencionices, pois desconsideram os artigos 165, 194, 195 e 239 da Constituição da República.” (FAGNANI, 2016). Se as renúncias fiscais fossem consideradas, mais R $\$ 22$ bilhões também integrariam as receitas previdenciárias, o que faria o Tesouro completar com $5 \%$ do todo das despesas previdenciárias uma conta de $\mathrm{R} \$ 16$ bilhões, ou 0,33\% do PIB (2016).

Corroborando, também, essa mesma linha de pensamento, Denise Lobato Gentil (2005, p. 23-40), em sua dissertação de mestrado, analisou o período compreendido entre o ano de 1990 a 2005 e constatou que houve déficit apenas no ano de 2003, sendo que, em 11 (onze) deles, ocorreu superávit e, em 5 (cinco) exercícios financeiros, o RGPS apresentou saldo operacional negativo, mas que, se fosse considerado o excedente dos recursos do caixa do Instituto Nacional da Seguridade Social (INSS) nos anos de 2004 e 2005 que atingiu, respectivamente, $\mathrm{R} \$ 8,2$ bilhões e $\mathrm{R} \$ 921$ milhões - “[...] não seria realista falar em crise previdenciária ou falência do sistema previdenciário diante de semelhante quadro financeiro." Ainda, acrescentou que, diante da diversidade das receitas, a previdência é monetariamente sustentável e expõe bom potencial para a expansão desses gastos com a população, não existindo crise, ao contrário do que é amplamente divulgado, no intuito de criar uma urgência por reforma nos benefícios, a fim de se evitar um desequilíbrio fiscal.

\section{CONCLUSÃO}

Destaca-se que o benefício da pensão por morte foi um dos primeiros direitos implementados entre a população, surgindo para determinados grupos e, depois, expandindo-se a todos seus contribuintes, visando guarnecer a família do segurado que viesse a óbito. Ocorre que esse benefício sofreu constantes alterações com o passar 
dos anos, algumas vezes em benefício do segurado e seus dependentes e, outras, nem tanto.

O presente trabalho teve como finalidade demonstrar a evolução histórica do benefício da pensão por morte aos dependentes do segurado até a implementação da Lei n. ${ }^{\circ}$ 13.135/2015, buscando esclarecer alguns motivos que levaram a isso, como a mudança na expectativa de vida da população brasileira de acordo com o IBGE e a necessidade de serem feitos ajustes fiscais.

Nesse sentido, como já demonstrado anteriormente, com a Lei n. ${ }^{\circ}$ 13.135/2015, fruto da conversão da MP n. ${ }^{\circ}$ 664/2014, acompanhada de diversas alterações, exclusões e inserções, modificou-se a concessão do aludido benefício aos dependentes dos segurados, passando-se a levar em consideração a sua idade e, também, a necessidade de utilização da renda do segurado falecido para a sobrevivência dos familiares (BRASIL, 2015).

Assim, se o óbito ocorrer depois de vertidas 18 contribuições mensais e pelo menos 2 anos após o início do casamento ou da união estável, ou se o óbito do segurado decorrer de acidente de qualquer natureza ou de doença profissional ou do trabalho, a pensão será paga pelo período de 3 anos a 20 anos, conforme a data do óbito do cônjuge, companheiro ou companheira na data do óbito, sendo que somente será vitalícia na data do óbito para aqueles que tiverem 44 anos de idade ou mais. Cabe ressaltar, no entanto, que, se o óbito ocorrer sem que o segurado tenha vertido 18 contribuições mensais, ou se o casamento ou a união estável tiverem sido iniciados em menos de 2 anos antes da data do óbito do segurado, a pensão será paga por apenas 4 meses ao cônjuge, companheiro ou companheira, salvo se o óbito do segurado decorrer de acidente de qualquer natureza ou de doença profissional ou do trabalho.

Outrossim, para dar continuidade às mudanças na Previdência Social e que não existiam antes da Lei n. ${ }^{\circ} 13.135 / 2015$, houve a inserção das regras em que o dependente condenado pela prática de crime doloso que resulte na morte do segurado, após o trânsito em julgado da sentença condenatória, não terá direito à pensão. Bem assim o cônjuge ou o companheiro que simular ou fraudar o casamento ou a união estável, com o fim de auferir o benefício previdenciário, também não a perceberá. 


\section{AS ALTERAÇÕES NA LEGISLAÇÃO DO BENEFÍCIO PENSÃO POR MORTE E SEUS REFLEXOS}

Conclui-se, então, que as constantes mudanças ocorridas na sociedade trouxeram consigo a necessidade de uma nova reestruturação e a positivação das normas de concessão de alguns benefícios da Previdência Social, como é o caso da aludida pensão por morte. Ainda, vale destacar que essas medidas se tornaram imprescindíveis para que haja um maior equilíbrio financeiro e atuarial.

\section{REFERÊNCIAS}

ALVES FILHO, Garibaldi; BELCHIOR, Miriam Aparecida; MANTEGA, Guido. EMI no 00023/2014 MPS MF MP. Exposição de Motivos da Medida Provisória n ${ }^{\circ} 664$ de 30 de dezembro de 2014. In: Diário Oficial da República Federativa do Brasil, Brasília, DF, 02 jan. 2015. Disponível em: <http://www.planalto.gov.br/ccivil_03/ Ato2011-2014/2014/Mpv/mpv664.htm>. Acesso em: 2 de mar. $20 \overline{1} 6$.

AMADO, Frederico. Direito Previdenciário. 7. ed. rev. ampl. e atual. Salvador: JusPODIVM, 2016.

BRASIL. Constituição da República Federativa do Brasil de 1988. Dispõe sobre a instituição do Estado Democrático de Direito, direito e deveres dos cidadãos e outras normas. Diário Oficial da União, Brasília, DF, 1988. Disponível em: $<$ http://www.planalto.gov.br/ ccivil_03/constituicao/constituicaocompilado.htm>. Acesso em: 5 de abr. $2 \overline{0} 16$.

Presidência da República. Lei no 13.135 de 17 de junho de 2015. Discorre sobre alterações em leis previdenciárias. Diário Oficial da União, Brasília, DF, 2015b. Disponível em: <http://www.planalto. gov.br/ccivil_03/_Ato2015-2018/2015/Lei/L13135.htm>. Acesso em: 1 abr. 2016.

Lei no 8.213 de 24 de julho de 1991. Dispõe sobre os Planos de Benefícios. Diário Oficial da União, Brasília, DF, 1991. Disponível em:<http://www.planalto.gov.br/ccivil_03/leis/L8213cons. $\mathrm{htm}>$. Acesso em: 10 de mai. 2016.

. Medida Provisória 664 de 30 de dezembro de 2014.

Prevê alterações nas Leis $\mathrm{n}^{\mathrm{os}_{\mathrm{s}}} 8.213 / 91, \mathrm{n}^{\mathrm{o}} 10.876 / 04, \mathrm{n}^{\mathrm{o}} 8.112 / 90$,

e a Lei $n^{\circ}$ 10.666/03. Diário Oficial da União, Brasília, DF, 2014.

Disponível em: $<$ http://www.planalto.gov.br/ccivil_03/_Ato20112014/2014/Mpv/mpv664.htm>. Acesso em: 2 mar. $201 \overline{6}$.

CASTRO, C. A. P. de; LAZZARI, J. B. Manual de Direito

Previdenciário. 8. ed. Florianópolis: Conceito Editorial, 2007. 


\section{DEPARTAMENTO INTERSINDICAL DE ESTATÍSTICA E} ESTUDOS SOCIOECONÔMICOS. A Situação do trabalho no Brasil na primeira década dos anos 2000. São Paulo: DIEESE, 2012. Disponível em: < http://www.dieese.org.br/livro/2012/ livroSituacaoTrabalhoBrasil.pdf $>$. Acessado em: 17 jun. 2016.

EXPECTATIVA de vida dos brasileiros sobe para 75,2 anos, diz IBGE. G1, São Paulo, dez. 2015. Disponível em: < http://g1.globo. com/ciencia-e-saude/noticia/2015/12/expectativa-de-vida-dosbrasileiros-sobe-para-752-anos-diz-ibge.html>. Acesso em: 30 jun. 2016.

FAGNANI, E. A Previdência social não tem déficit. Plataforma Política Social, [S. 1.], fev. 2016. Sem paginação. Disponível em: $<$ http://plataformapoliticasocial.com.br/a-previdencia-social-nao-temdeficit/>. Acesso em: 10 jun. 2016.

GENTIL, D. L. A Política Fiscal e a Falsa Crise da Seguridade Social Brasileira - Análise financeira do período 1990-2005. 2006. Tese (Doutorado em Economia ) - Instituto de Economia da Universidade Federal do Rio de Janeiro, Rio de Janeiro, 2006. Disponível em: $<$ http://www.ie.ufrj.br/images/pesquisa/publicacoes/teses/2006/a politica_fiscal_e_a_falsa_crise_da_seguraridade_social_brasileira analise_financeira_do_periodo_1990_2005.pdf>. Acesso em: 15 jun. 2016.

GOES, H. M. Manual de direito previdenciário. 4. ed. Rio de Janeiro: Ed. Ferreira, 2011.

IBRAHIM, F. Z. Curso de Direito Previdenciário. 20. ed. Rio de janeiro: Impetus, 2015.

MARTINS, S. P. Direito da seguridade social. 34. ed. São Paulo: Atlas, 2014.

MELO, F. Os impactos das mudanças demográficas na Seguridade Social e o ajuste fiscal. Plataforma Política Social, [S. 1.], jun. 2016. Artigo 30. Disponível em: < http://plataformapoliticasocial.com.br/ artigo-30-os-impactos-das-mudancas-demograficas-na-seguridadesocial-e-o-ajuste-fiscal/\#_ftn3>. Acesso em: 22 jun. 2016.

ROCHA, D. M. da; BALTAZAR JÚNIOR, J. P. Comentários à lei de benefícios da previdência social. 9. ed. rev. ampl. e atual. Porto Alegre: Livraria do Advogado: Esmafre, 2009.

SANTOS, M. F. dos. Direito previdenciário esquematizado. São Paulo: Saraiva, 2011. 


\section{AS ALTERAÇÕES NA LEGISLAÇÃO DO BENEFÍCIO PENSÃO POR MORTE}

E SEUS REFLEXOS

\section{NOTAS:}

Criou as caixas de aposentadorias e pensões que concedia aos empregados de cada empresa ferroviária os benefícios de pensão por morte, aposentadoria por invalidez e aposentadoria ordinária ou por tempo de contribuição. Essa lei estendeu-se a uma grande parcela de trabalhadores brasileiros e mais tarde unificou essas caixas e pensões, resultando na Caixa de aposentadorias e pensão dos empregados ferroviários e empregados em serviço público. E, dez anos depois, os mesmos, foram divididos em categorias profissionais, ou seja, a cada nova implementação, mais trabalhadores eram beneficiados. (GOES, 2011).

${ }^{2} \mathrm{O}$ art. $5^{\circ}$ da Lei $\mathrm{n}^{\circ} 13.135 / 2015$ determina que todos os atos praticados durante a vigência da $\mathrm{MP}^{\circ}$ 664/2014 sejam revistos e adaptados de acordo com a nova lei para que os segurados não restem prejudicados com as alterações. 
